\title{
Rasm Utsmani Dalam Al-Qur'an Indonesia Pada Kelompok Pemuda Amor (Arek Mor Lorong) Kecamatan Lenteng Sumenep
}

\author{
${ }^{1}$ Khairul Muttaqin, Jamal Abd. Nasir \\ Institut Agama Islam Negeri Madura \\ 1muttaqin.ilunks@gmail.com
}

\begin{abstract}
The Ottoman rasm was the method of writing agreed upon by the companions of the Prophet Muhammad in codifying the Qur'an which was feared lost and destroyed if it was not immediately codified. The Qur'an at that time was written without adding vowel and letter dots in the writing. However, the The companions of prophet MUHAMMAD SAW can read it because of the Arabic fluency of the companions and a high level of memorization. Over time the writing of the Koran began to add vowel and letter dots because generations after the companions found it difficult to read the Koran without punctuation such as vowel and dots on the letter. The al-Qur'an published by the Ministry of Religion of the Republic of Indonesia has experienced many improvements in its writing, but there are ways of writing the Ottoman Manuscripts that are still contained in the Qur'an published by the Ministry of Religion of the Republic of Indonesia. This can cause errors if not explained how to read it. Because of that, community service was carried out about the Ottoman rasm in the Qur'an. The target group for community service activities is the youth group AMOR (Arek Mor Lorong) Lenteng Sumenep. The target group does not yet have the knowledge and skills to read the Ottoman rasm written in the Indonesian Qur'an. Therefore, in this community service activity, material about Ottoman rasm was delivered in the Indonesian Qur'an. As a result, the youth group AMOR (Arek Mor Lorong) Lenteng Sumenep finally gained in-depth knowledge about the Ottoman rasm found in the Indonesian Qur'an.
\end{abstract}

Keyword: Rasm Ottoman, Qur'an, Amor

\begin{abstract}
Abstrak
Rasm utsmani merupakan cara penulisan yang disepakati oleh para sahabat Rasulullah Muhammad SAW dalam mengkodifikasi al-Qur'an yang dihawatirkan hilang dan musnah jika tidak segera dikodifikasi. Al-Qur'an pada zaman tersebut ditulis tanpa menambahkan harokat dan titik dalam penulisannya. Meski demikian, para sahabat dapat membacanya karena kefasihan bahasa arab para sahabat dan tingkat hafalan yang tinggi. Seiring berjalannya waktu penulisan al-Qur'an mulai ditambahkan harokat dan titik karena generasi setelah sahabat merasa susah membaca al-Qur'an tanpa tanda baca seperti harokat dan titik pada huruf tersebut. Adapun al-Qur'an yang diterbitkan oleh Kementerian Agama Republik Indonesia telah banyak mengalami penyempurnaan dalam penulisannya, namun terdapat cara penulisan mushaf utsmani yang masih terdapat dalam al-Qur'an terbitan Kementerian Agama Republik Indonesia. Hal ini dapat menimbulkan kesalahan jika tidak dijelaskan cara membacanya. Karena itu maka dilakukan kegiatan pengabdian pada masyarakat tentang rasm utsmani di alQur'an Indonesia. Kelompok yang menjadi sasaran kegiatan pengabdian kepada masyarakat ini adalah kelompok pemuda AMOR (Arek Mor Lorong) Lenteng Sumenep. Kelompok sasaran tersebut belum memiliki pengetahuan dan keterampilan untuk membaca gaya penulisan rasm utsmani yang terdapat dalam al-Qur'an Indonesia. Karena itulah, dalam kegiatan pengabdian kepada masyarakat ini disampaikan materi tentang rasm utsmani dalam al-Qur'an Indonesia. Hasilnya, kelompok pemuda AMOR (Arek Mor Lorong) Lenteng Sumenep akhirnya mendapatkan pengetahuan yang mendalam tentang rasm utsmani yang terdapat dalam alQur'an Indonesia.
\end{abstract}




\section{Deskripsi}

Membaca al-Qur'an merupakan satu hal yang dianjurkan dalam agama Islam. Disebutkan dalam hadits-hadits Nabi bahwa membaca satu huruf dalam al-Qur'an akan dibalas dengan sepuluh kebaikan. Sudah semestinya umat Islam memiliki pengetahuan yang memadai tentang membaca al-Qur'an dengan baik dan benar.

Di era modern ini masyarakat Indonesia yang mayoritas beragama Islam banyak masih belum memiliki pengetahuan yang cukup dalam membaca al-Qur'an dengan baik dan benar. Bahkan banyak mahasiswa di perguruan tinggi Islam yang belum bisa membaca al-Qur'an dengan baik dan benar.

Hal ini harus dimulai dari tingkatan yang lebih rendah dari tingkatan mahasiswa agar mahasiswa yang akan masuk di perguruan tinggi agama Islam memiliki pengetahuan yang memadai dan mampu membaca al-Qur'an dengan baik dan benar.

Berkaitan dengan hal tersebut maka dipandang penting dan perlu untuk mengadakan pendidikan atau penyuluhan kepada masyarakat, lebih tepatnya siswa dan siswa di sekolah-sekolah negeri atau swasta, agar memiliki kemampuan membaca al-Qur'an dengan baik.

Jika membaca saja tidak lancar maka jelas untuk memahami kandungan ayatnya menjadi lebih sulit lagi. Jika umat Islam sendiri sudah tidak mampu untuk membaca dan memahami kandungan ayat suci al-Qur'an maka tidak lama lagi alQur'an akan tinggal namanya saja dan teks-teks ayat al-Qur'an akan menjadi teks sakral belaka yang tidak begitu berpengaruh pada kehidupan masyarakat Islam.

Untuk bisa membaca dengan lancar dan tidak terjadi kesalahan maka harus mengusai tata cara penulisan rasm utsmani yang terdapat di dalam al-Qur'an. Rasm utsmani merupakan tata cara penulisan al-Qur'an yang dibakukan pada masa khalifah Utsman bin Affan.

Tata cara penulisan al-Qur'an di Indonesia (al-Qur'an versi Departemen Agama) memang sudah mengalami perubahan dan tidak sama persis seperti alQur'an mushaf utsmani namun lebih seperti tata cara penulisan rasm imla'i.

Namun beberapa model dan cara penulisan al-Qur'an Mushaf Utsmani masih terdapat di dalam al-Qur'an Indonesia. Karena itulah maka sudah seharusnya masyarakat Indonesia mengerahui tentang hal tersebut. Hal ini tentu saja agar terhindar dari berbagai macam kesalahan dalam membaca al-Qur'an.

Adapun pelaksanaan kegiatan pengabdian pada masyarakat ini akan dijabarkan secara detail sebagai berikut:

\section{Lokasi dan komunitas sasaran}

Kegiatan Pengabdian Kepada Masyarakat (PKM) ini dilaksanakan di Kecamatan Lenteng Kabupaten Sumenep Madura. Dalam prosesnya, penyampaian materi PKM ditempatkan di musholla Miftahul Hasanah Lenteng Sumenep.

Sasaran kegiatan ini adalah AMOR (Arek Mor Lorong) Lenteng Sumenep. Arek Mor Lorong tersebut merupakan siswa dan siswi yang bertempat tinggal di timurnya jalan raya di desa Lenteng timur Lenteng Sumenep.

Arek Mor Lorong yang menjadi komunitas sasaran kegiatan pengabdian kepada masyarakat ini berbeda-beda tingkatan pendidikannya. Sebagian adalah siswi Madrasah Tsanawiyah dan sebagian lainnya adalah siswi Madrasah Aliyah.

Arek Mor Lorong yang menjadi komunitas sasaran kegiatan pengabdian kepada masyarakat ini berjumlah sekitar 20 orang dari tingkatan Madrasah Tsanawiyah dan Madrasah Aliyah.

Seluruh Arek Mor Lorong yang menjadi komunitas sasaran kegiatan pengabdian kepada masyarakat ini bermukim atau tinggal di timur jalan raya desa lenteng Timur Lenteng Sumenep. Hal ini menjadikan pengabdi menjadi lebih nyaman dalam mengkondisikan komunitas sasaran kegiatan pengabdian kepada masyarakat karena komunitas sasaran beraa di tempat yang berdekatan dan mudah dijangkau. 


\section{Pelaksanaan PKM}

Dalam pelaksanaan pengabdian pada masyarakat terdapat dua tahapan yang dilakukan yakni tahap persiapan dan tahap pelaksanaan. Pada tahapan yang pertama yakni tahap persiapan dilaksanakan beberapa persiapan agar kegiatan pengabdian kepada masyarakat (PKM) ini bisa terlaksana dengan maksimal dan memberikan manfaat yang banyak bagi sasaran komunitas kegiatan pengabdian kepada masyarakat ini.

Persiapan yang dilakukan antara lain adalah menyiapkan materi yang akan disampaikan kegiatan pengabdian kepada masyarakat ini. Materi yang dimaksud adalah materi tentang rasm utsmani dalam al-Qur'an. Materi kegiatan pengabdian kepada masyarakat tersebut dibagi menjadi tiga bagian yakni materi rasm utsmani, rasm utsmani dalam al-Qur'an bagian 1 dan rasm utsmani dalam al-Qur'an bagian 2 .

Dalam rasm utsmani diuaraikan tentang definisi rasm utsmani, sejarah tulisan sebelum dan sesudah Islam datang dan perkembangan penulisan rasm utsmani.

Dalam materi Rasm utsmani dalam al-Qur'an bagian 1 diauraikan tentang contoh-contoh tulisan al-Qur'an mushaf utsmani yang masih belum ada harokat dan titiknya.

Dalam materi Rasm utsmani dalam al-Qur'an bagian 2 diuraikan tentang tulisan utsmani yang ada di dalam al-Qur'an Indonesia.

Selain itu juga dipersiapkan pulpen dan foto copi materi yang akan diberikan kepada peserta. Dalam proses persiapan juga dibuat banner acara pengabdian kepada masyarakat, konsusmsi berupa roti dan air mineral.

Pelaksanaan acara kegiatan pengabdian kepada masyarakat ini berjalan dengan sukses dan lancar sesuai dengan yang sudah direncanakan. Pemateri menyampaikan materi dengan baik dan komunitas yang menjadi sasaran kegiatan pengabdian kepada masyarakat ini menerima materi dengan baik pula.

Adapun jadual yang telah direncanakan tercantum dalam table berikut:

\begin{tabular}{|c|c|c|c|c|c|}
\hline No & Materi & Pemateri & Tanggal & Waktu & Tempat \\
\hline 1 & Rasm utsmani & $\begin{array}{c}\text { Jamal Abd. } \\
\text { Nasir }\end{array}$ & $\begin{array}{c}12-07- \\
2019\end{array}$ & 19.00 & $\begin{array}{c}\text { Musholla } \\
\text { Miftahul } \\
\text { Hasanah } \\
\text { Lenteng }\end{array}$ \\
\hline 2 & $\begin{array}{c}\text { Rasm utsmani } \\
\text { dalam al-Qur'an } \\
\text { bagian 1 }\end{array}$ & Khairul Muttaqin & $\begin{array}{c}13-07- \\
2019\end{array}$ & 19.00 & $\begin{array}{c}\text { Musholla } \\
\text { Miftahul } \\
\text { Hasanah } \\
\text { Lenteng }\end{array}$ \\
\hline 3 & $\begin{array}{c}\text { Rasm utsmani } \\
\text { dalam al-Qur'an } \\
\text { bagian 2 }\end{array}$ & Khairul Muttaqin & $\begin{array}{c}14-07- \\
2019\end{array}$ & 19.00 & $\begin{array}{c}\text { Musholla } \\
\text { Miftahul } \\
\text { Hasanah } \\
\text { Lenteng }\end{array}$ \\
\hline
\end{tabular}

Meskipun waktu kegiatan dilksanakan pada malam hari namun kelompok sasaran tetap antusias dalam menerima penjelasan dari pemateri. Pemilihan waktu malam karena di pagi, siang dan sore hari kelompok sasaran memiliki kesibukan masing-masing seperti sekolah, berolahraga dan sebagainya.

\section{Penyampaian Materi PKM}

Pada bagian sebelumnya sudah dijelaskan bahwa materi kegiatan pengabdian kepada masyarakat ini dibagi menjadi tiga bagian. Materi Rasm utsmani dilaksanakan pada tanggal 12 Juli 2019 oleh Jamal Abd. Nasir, Lc., M.Th.I. 


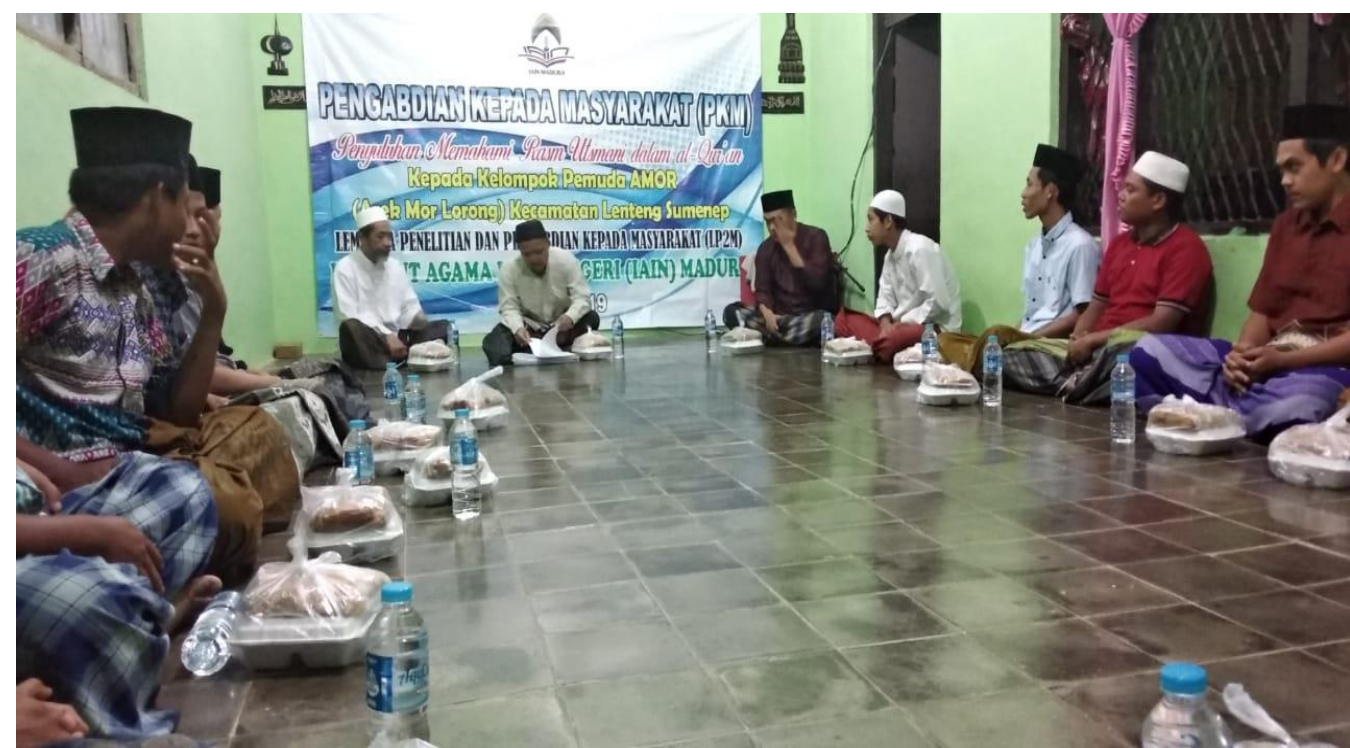

Gambar 1: Penyampain Materi Oleh Jamal Abd. Nasir, Lc., M.Th.I.

Pada materi tersebut diuraikan bagaimana al-Qur'an pertama kali ditulis dan dibukukan oleh para sahabat Nabi Muhammad SAW tanpa harokat dan titik sampai akhirnya diberikan tanda-tanda baca seperti harokat, titik, tanda panjang, tanda berhenti, tanda tidak boleh berhenti dan sebagainya.

Adapun pada materi Rasm utsmani dalam al-Qur'an bagian 1 dijelaskan beberapa contoh tulisan al-Qur'an mushaf utsmani yang belum disertai titik dan harokah. Kelompok sasaran merasa heran karena al-Qur'an yang tidak diberikan titik dan harokah bisa dibaca dengan baik oleh para sahabat Nabi Muhammad SAW.

Pada materi Rasm utsmani dalam al-Qur'an bagian 2 dijelaskan tentang tulisan utsmani yang ada di dalam al-Qur'an Indonesia seperti menyambung dan memisah huruf, membuang dan menetapkan huruf dan ha' ta'nits yang dalam al-Qur'an ditulis dengan ta' majrurah.

\section{Analisis Keberhasilan}

Kegiatan Pengabdian Kepada Masyarakat ini berjalan dengan sukses dan memberikan dampak yang positif pada Arek Mor Lorong Lenteng Sumenep dalam memahami rasm utsmani dalam al-Qur'an.

Adanya tulisan-tulisan utsmani yang masih tetap ada dalam al-Qur'an mushaf Indonesia menjadikan kelompok sasaran awalnya merasa aneh dengan model tulisan tersebut. Namun setelah dijelaskan alasan menyambung dan memisah huruf, membuang dan menetapkan huruf dan ha' ta'nits yang dalam al-Qur'an ditulis dengan ta' majrurah akhirnya kelompok sasaran dapat memahami dan dapat terhindar dari kesalahan saat membaca al-Qur'an.

\section{Temuan}

Arek Mor Lorong awalnya tidak mengetahui bahwa al-Qur'an yang tersebar luas di wilayah Indonesia dulunya tidak seperti al-Qur'an saat ini. Arek Mor Lorong tidak tahu awalnya bahwa al-Qur'an zaman Rasulullah dan zaman sahabat Nabi tidak menggunakan tanda baca seperti harokat, titik pada huruf, tanda waqaf dan lain sebeagainya.

Arek Mor Lorong terkejut ketika ditunjukkan print out al-Qur'an zaman dahulu yang tidak berharokat dan tidak disertai titik pada huruf. Print out tersebut layaknya seperti tulisan jimat yang tidak bisa dibaca dan dipahami. 


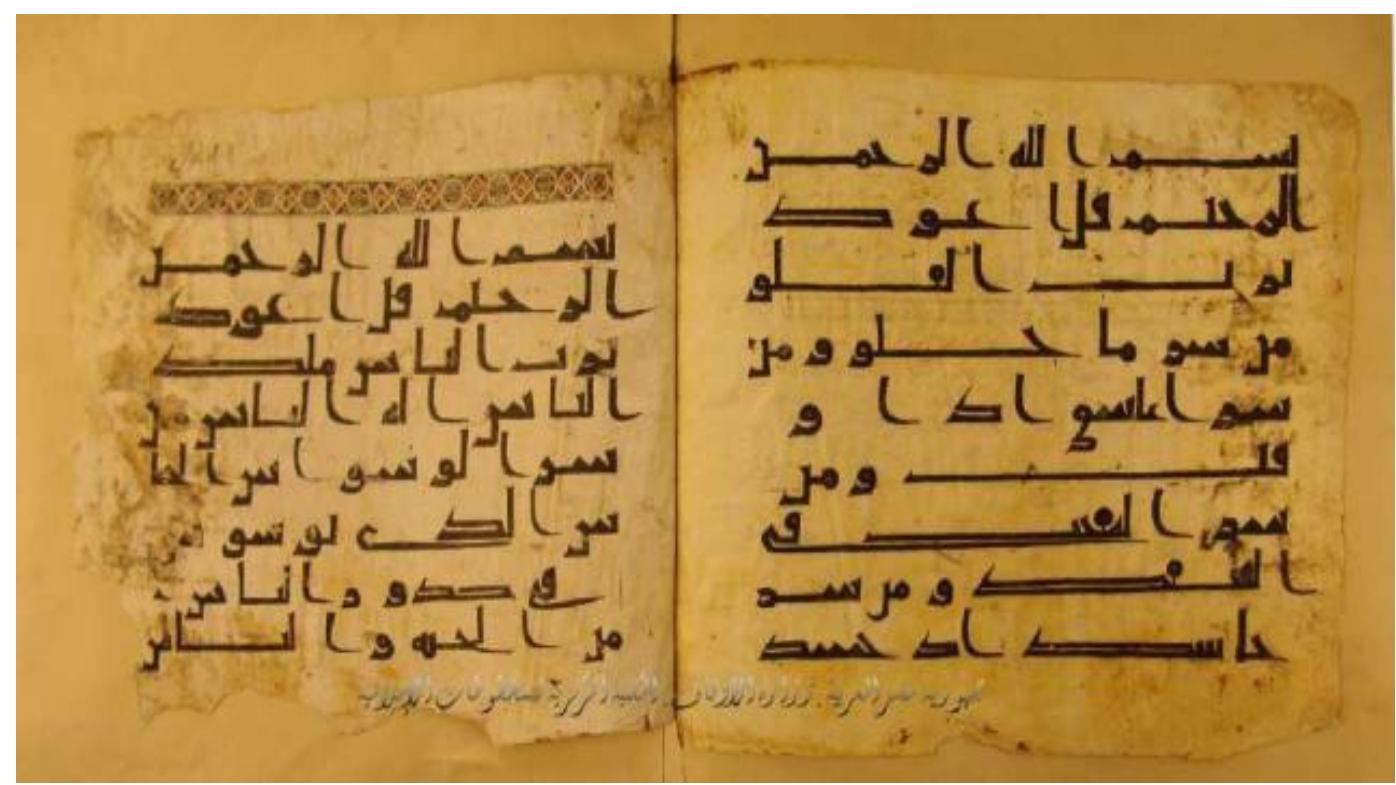

Gambar 2: Mushaf Utsmani Tanpa Harokat dan Titik

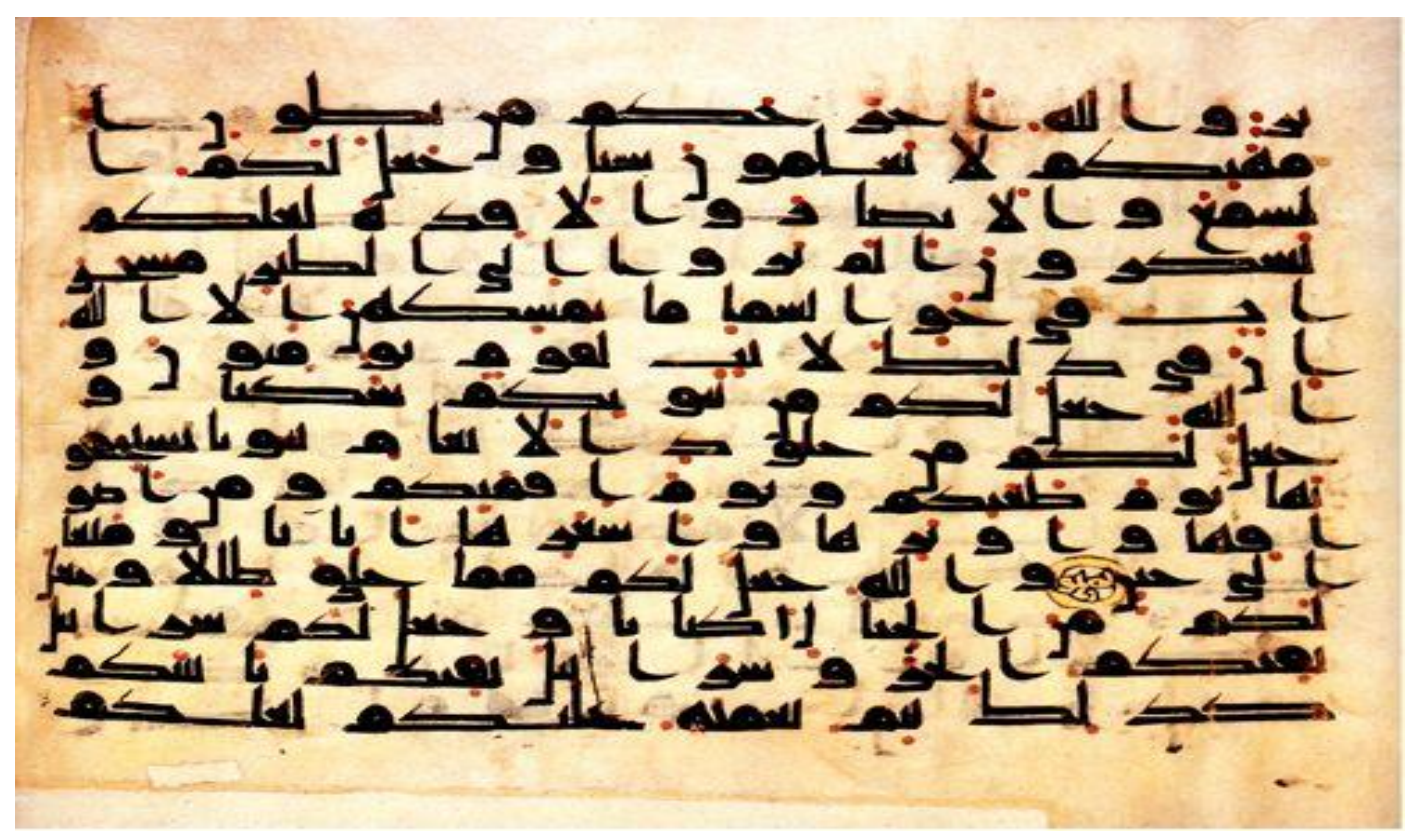

Gambar 3: Mushaf Utsmani Tanpa Harokat dan Titik 


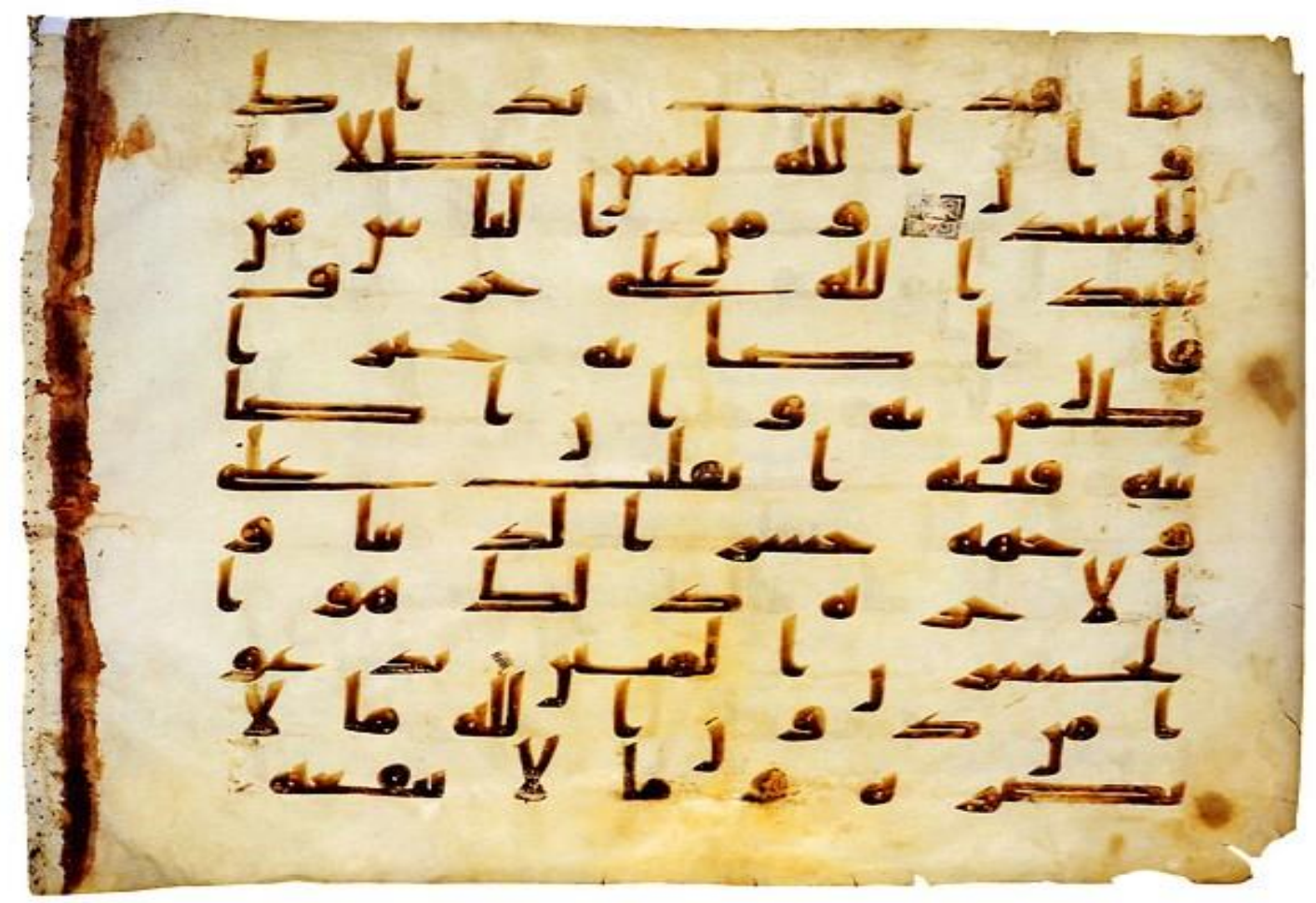

Gambar 4: Mushaf Utsmani Tanpa Harokat dan Titik

Arek Mor Lorong ketika ditunjukkan tulisan rasm utsmani yang masih ada pada al-Qur'an di Indonesia tidak merasa heran dan dianggap biasa. Kata آنْ لَّ yang dipisah penulisannya dan kata آلَّم yang disambung penulisannya seakan tidak ada perbedaannya. Hal ini akan menimbulkan kesalahan dalam membaca al-Qur'an jika tidak bisa membedakan kata yang bacaannya sama tapi berbeda dalam penulisan dalam hal menyambung dan memisahkannya. Dua kata tersebut memang sama dalam cara membacanya namun berbeda ketika diwaqafkan. Jika ditulis terpisah maka boleh berhenti di tengah (pada lafadz an), namun jika disambung penulisannya maka tidak boleh berhenti di tengah kata.

رَحْمَت yang ditulis dengan ta' majrurah. Sepintas Arek Mor Lorong tidak merasa aneh dan menganggap biasa penulisan tersebut. Namun penulisan kata rahmat dan lafadz yang lain yang ditulis dengan ta' marbuthah dan ta' majrurah terdapat perbedaan yang signifikan. Ketika washal maka tidak perbedaan dalam membacanya. Namun jika diwaqafkan maka terdapat perbedaan. Jika ditulis dengan ta' marbuthah maka waqafnya dengan ha' dan jika ditulis dengan ta' majrurah maka waqafnya dengan ta'.

Pemahaman beberapa kaidah-kaidah rasm al-Qur'an mushaf utsmani yang masih terdapat dalam al-Qur'an Indonesia akan mampu menghindarkan pembaca terjatuh pada kesalahan. Jika tidak memahami kaidah tersebut maka tentu saja akan terjadi kesalahan dalam membaca al-Qur'an pada lafadz-lafadz tersebut.

\section{Rekomendasi}

Materi tentang rasm al-Qur'an, Rasm utsmani dalam al-Qur'an bagian 1 dan Rasm utsmani dalam al-Qur'an bagian 2 merupakan materi yang harus dipahami setiap individu yang hendak membaca al-Qur'an. Namun, selain materi tersebut terdapat materi lain yang tidak kalah penting dan harus dipahami oleh setiap individu dalam membaca al-Qur'an.

Dengan demikian maka penting untuk dilakukan pengabdian lanjutan agar didapatkan hasil yang benar-benar maksimal dan mengetahui secara detail tentang tata cara membaca al-Qur'an. 


\section{Kesimpulan}

Pengabdian kepada masyarakat oleh Program Studi IImu al-Qur'an dan Tafsir IAIN Madura dapat diuraikan dalam beberapa kesimpulan. Kegiatan penyuluhan memahami rasm utsmani dalam al-Qur'an pada kelompok pemuda Amor (Arek Mor Lorong) Lenteng Sumenep mendapatkan tanggapan dan reaksi positif dari kelompok sasaran dan ketua Amor Lenteng Sumenep dan stakeholder. Kegiatan dilaksanakan dengan penyampaian materi tentang rasm utsmani dan rasm utsmani dalam al-Qur'an Indonesia. Kegiatan ini memberikan manfaat yang sangat banyak kepada kelompok sasaran yakni kelompok pemuda Amor Lenteng Sumenep. Kelompok pemuda Amor Lenteng Sumenep semula tidak memahami beberapa tulisan rasm utsmani yang ada dalam al-Qur'an Indonesia seperti kata رَخْمَ yang ditulis dengan ta' marbuthah dan kata jَحَمَت yang ditulis dengan ta' majrurah yang cara bacanya berbeda saat

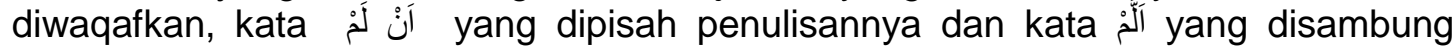
penulisannya berbeda ketika diwaqafkan dan lain sebagainya. Dengan penjelasan yang mendetail dan diberikan contoh-contoh ayat dalam al-Qur'an, kelompok pemuda Amor bisa memahami dan bisa menghindarkan dari kesalahan saat membaca alQur'an.

\section{Daftar Pustaka}

Hammad, Ghanim Quddari, Al-Muyassar fi 'Ilmi Rasm al-Mushafi wa Dhabtihi. t,k: Markaz Dirasat wa al-Ma'lumatu al-Qur'aniyah bi Ma'had Imam.

Hammad, Ghanim Quddari, Rasm al-Mushaf Dirasatun Lughawiyatun Tarikhiyatun, T,K: T.P, 1982.

Mannan, Moh. Romzi al-Amiri. Dasar-Dasar Ilmu Tajwid Lengkap. Probolinggo: Pusat Pendidikan IImu al-Qur'an Pondok Pesantren Nurul Jadid Paiton Probolinggo, 1995.

Muhammad, Sya'ban bin Isma'il, Rasm al-Mushafi wa Dhabtuhu Baina Tauqif wa alIstilahati al-Hadisat, Qahirah: Dar al-Salam, 2012.

RI, Departemen Agama, Pedoman Umum Penulisan dan Pentashihan Mushaf AlQur'an, Badan Penelitian dan Pengembangan Agama: Puslitbang Lektur Agama, 1999

Al-Hamidy, Abd Qadir Umar Usman, "Penulisan Al-Qur'an dengan Rasm Uthmani di antara Tawqif dan ljtihad", Ma'alim Al-Qur'an wa Al-Sunnah, Vol. 14, No. 2, 2018.

Arifin, Zainal, "Mengenal Rasm Al-Qur'an", Suhuf, Vol. 5, NO. 1, 2012.

Madzkur, Zaenal Arifin, "Urgensi Rasm Utsmani”, Jurnal Khatulistiwa, Vol. 1, No. 1, Maret 2011 